\title{
Morton Neuroma
}

National Cancer Institute

\section{Source}

National Cancer Institute. Morton Neuroma. NCI Thesaurus. Code C4075.

Swelling and inflammation of the nerve between the ends of the metatarsal bones at the base of the toes. It is caused by compression of the nerve, usually between the third and fourth toes. It results in a burning, sharp pain and numbness on the bottom of the foot in the area involved. Symptoms may resolve by resting the foot, taking anti-inflammatory drugs, applying ice packs, or injecting cortisone at the site. Persistent symptoms require surgical excision of the affected nerve. 